\title{
Simultaneous L4-5 Transforaminal and L5-S1 Interlaminar Percutaneous Endoscopic Lumbar Discectomy for L4-5 Down Migrated Disc: A Case Report
}

\author{
Sang Soo Eun ${ }^{1}$, Sang-Ho Lee ${ }^{2}$ \\ Departments of ${ }^{1}$ Orthopaedic Surgery, ${ }^{2}$ Neurosurgery, Spine Health Wooridul Hospital (SHWH) Gang Nam, Seoul, Korea
}

Corresponding Author: Sang Soo Eun, MD, PhD Department of Orthopaedic Surgery, Spine Health

Wooridul Hospital (Gangnam), 445, Hakdong-ro, Gangnam-gu, Seoul 06068, Korea

Tel: +82-2-513-8947, Fax: +82-2-513-8154

E-mail: erupt0123@naver.com

Received: March 29, 2016,

Revised: May 23, 2016

Accepted: June 1, 2016

\begin{abstract}
A 44 years-old woman was diagnosed as L4-5 down migrated disc herniation and decided for percutaneous endoscopic lumbar discectomy (PELD). Since significant amount of disc material is present in both subannular lesion and down migrated portion, transforaminal approach for L4-5 and interlaminar approach for L5-S1 were planned. Herniated disc was successfully removed. Simultaneous transforaminal and interlaminar PELD can be an minimal invasive option for treatment of migrated disc herniation in selected cases.
\end{abstract}

Key Words: PELD, Transforaminal, Interlaminar, Simultaneous, Migrated disc

\section{INTRODUCTION}

Choi et al. ${ }^{2)}$ reported L5-S1 interlaminar approach to treat L4-5 down migrated disc herniation. Developed from this previous technique, authors present a technical case report for simultaneous L4-5 transforaminal and L5-S1 interlaminar PELD in $L 4 / 5$ down migrated disc herniation.

\section{CASE REPORT}

A 44 years-old woman presented with severe left lower extremity radiating pain and back pain, and ambulation was not possible. MRI showed left sided large amount of disc herniation with down migration at L4-5 (Fig. 1). The patient did not want open surgery nor general anesthesia. We decided for percutaneous endoscopic lumbar discectomy (PELD). Since significant amount of disc material is present in both subannular lesion and down migrated portion, transforaminal approach for L4-5 and interlaminar approach for L5-S1 were planned. Left side transforaminal approach at L4-5 was first performed to decompress subannular disc herniation (Fig. 2). Down migrated disc was also to be removed at transforaminal approach but forceps could not reach to grasp it. Rigid working channel was introduced through L5-S1 left interlaminar window. Down migrated herniated disc was seen just after splitting ligamentum flavum (Fig. 3). The multi-fragmented disc was removed completely (Fig. 4 and 5). Two $0.8 \mathrm{~cm}$ sized post-operative scars are observed. The pain disappeared and patient was discharged next day.

\section{DISCUSSION}

PELD is recognized as a minimal invasive surgical option for treatment of disc herniation. One of the biggest advantages of PELD is preservation of the soft and bony tissues that are usually resected in standard discectomy ${ }^{4}$. Other advantages include minimal anesthesia, shorter hospital stay, faster return to activities of daily living, lower estimated blood loss during
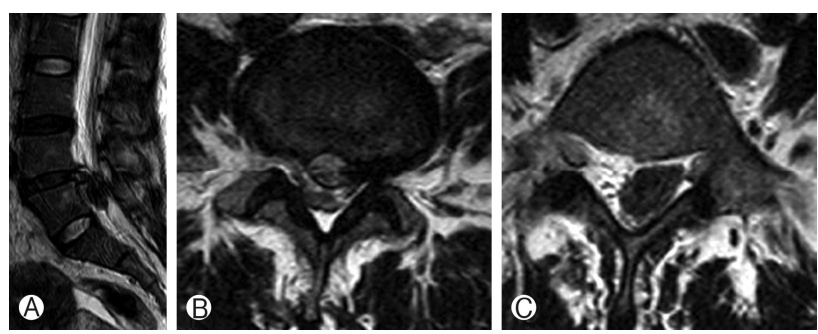

Fig. 1. (A) Sagittal MRI shows high-grade down-migrated $L 4-5$ disc herniation. (B) Axial MRI at L4-5 disc level shows significant amount subannular disc herniation. (C) Axial MRI at L5 lower pedicle level shows large amount of down migrated disc. 
surgery, lower cost of postoperative care, and lower infection rates $^{6}$. Open lumbar discectomy is gold standard to treat herniated disc and it is especially true in difficult case like this. Since this is only case report, superiority of the technique could not be proved but authors want to report one minimal invasive technique to treat down migrated disc herniation.

For treatment of migrated disc herniation, numerous methods have been proposed. Lee et al. ${ }^{5)}$ treated migrated disc herniations by "half and half technique" and "epiduroscopic technique". They reported that down migtrated below lower level pedicle showed unfavorable result and discourage PELD in those cases. Choi et al. ${ }^{1)}$ reported transforaminal foraminoplasty to approach for highly down migrated disc herniation. By removing part of facet joints, working channel can be tilted in steeper angle to reach down migrated disc. Kim et al. ${ }^{3)}$ reported transforaminal contralateral apparoch in highly down migrated disc to decrease chance of exiting nerve root damage. Choi et al. ${ }^{2)}$ reported treatment L4-5 down migrated disc herniation via L5-S1 interlaminar approach. Du et al. ${ }^{7)}$ reported good outcomes in treatment of down migrated disc via translaminar PELD.

Authors thought that it would be difficult to remove whole disc from only transforaminal or interlaminar approach. There would be insufficient decompression if only one approach was performed. Reason for not removing transforaminal working channel (Fig. 2) was that authors wanted to use triangulation technique as arthroscopic surgery which uses one portal as a viewing portal and the other as a working portal. However, disc fragments were well removed with each approach, and biportal manipulation was not necessary. Some would questions that
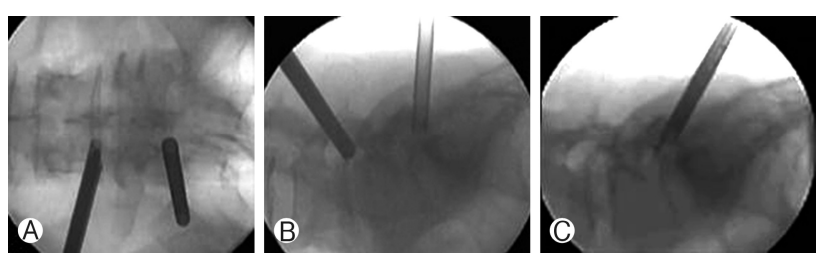

Fig. 2. (A) Antero-posterior and (B) Lateral view of intraoperative fluoroscopy showing placement of $\llcorner 4-5$ transforaminal and L5-S1 interlaminar rigid working channels. (C) Note caudal to cranial direction of working channel and how far up the focep can reach.
L4-5 transforaminal approach was really necessary. Amount of sub-annular disc could not be ignored and could not be removed by interlaminar approach from L5-S1. From L4-5 transforaminal approach, complete removal of down migrated disc fragment could be expected in if forcep can grasp part of all herniated fragments. This is easy if there is only one fragment. However in this case, there were multiple fragments and could not be

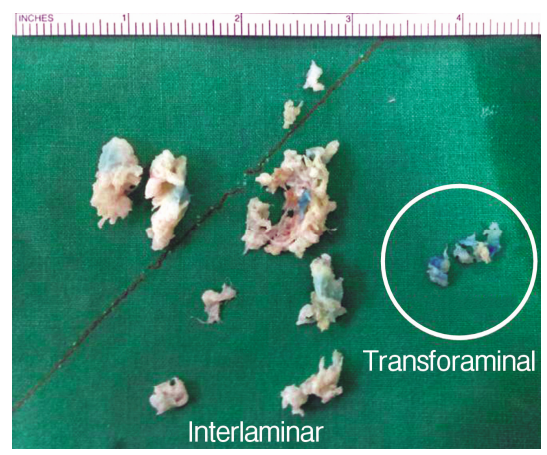

Fig. 4. Picture shows removed multiple fragments of herniated disc. Disc fragments removed from transforaminal approach are inside the circle. Note large sized disc materials from interlaminar approach.

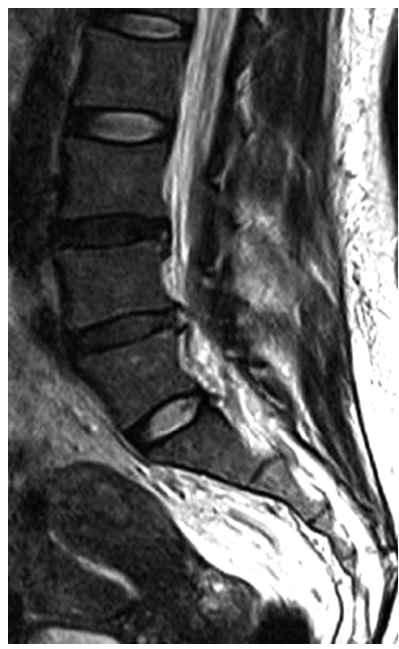

Fig. 5. Postoperative sagittal MRI shows complete removal of disc.
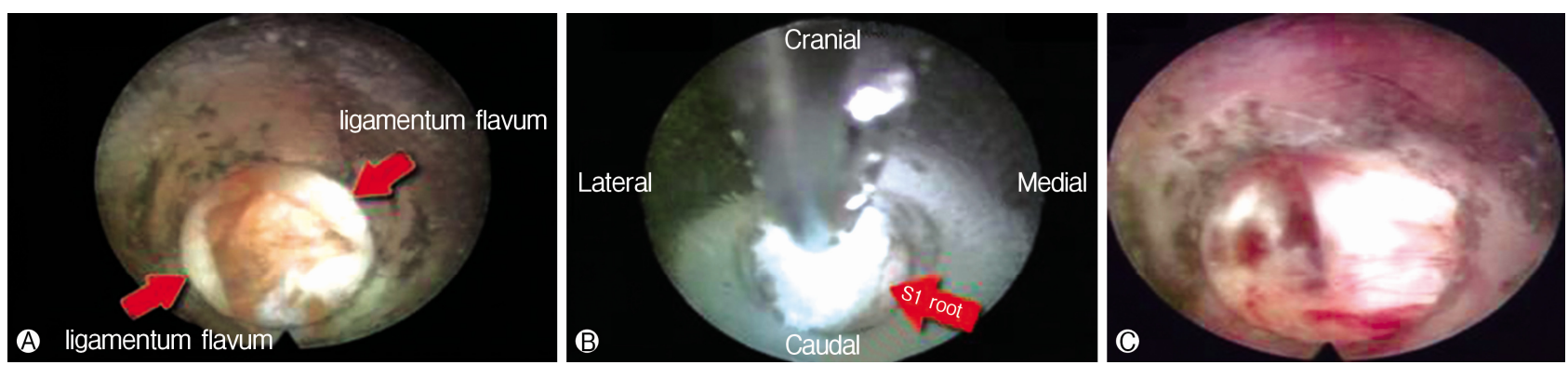

Fig. 3. Intraoperative endoscopic pictures of interlaminar approach (A) Down migrated disc was seen just after splitting ligamentum flavum. (B) Blue stained herniated disc is seen next to left side of S1 root. (C) S1 root is observed after removal of disc. 
removed from transforaminal approach. Still, $L 4-5$ transforaminal approach should precede interlaminar approach in $L 45$ down migrated disc herniation, if surgeons think subannular disc is large and should be removed because surgery can be finished with only transforaminal approach.

Indication of this technique is limited to L4-5 down migrated disc with wide L5-S1 interlaminar window. This technique is similar from previous technical note for L4-5 down migrated disc herniation via L5-S1 interlaminar approach ${ }^{2)}$. Choi et al. ${ }^{2)}$ did not define criteria for wide L5-S1 interlaminar window. Wide interlaminar window can be referred as upper roof of interlaminar space should be at least above the anatomical line bisecting the midpedicular level of L5 on the coronal image or AP X-ray. Diameter of working channel is about $8 \mathrm{~mm}$. Surgeons can measure preoperatively in AP X-ray that interlaminar window of ipsilateral side can accommodate $8 \mathrm{~mm}$ diameter working channel. Once working channel is introduced in epidural space, working channel should be tilted caudally in maximum angle and approach to L4-5 down migrated disc is possible.

\section{CONCLUSION}

Simultaneous transforaminal and interlaminar PELD can be an minimal invasive option for treatment of migrated disc herniation in selected cases.

\section{ACKNOWLEDGEMENT}

This study was supported by a grant from Spine Health Wooridul Hospital Foundation.

\section{REFERENCES}

1. Choi G, Lee SH, Lokhande P, Kong BJ, Shim CS, Jung B, et al: Percutaneous endoscopic approach for highly migrated intracanal disc herniations by foraminoplastic technique using rigid working channel endoscope. Spine 33:508-515, 2008

2. Choi G, Prada N, Modi H N, Vasavada N B, Kim J-S, Lee S-H: Percutaneous endoscopic lumbar herniectomy for high-grade down-migrated L4-L5 disc through an L5-S1 interlaminar approach: a technical note. Minim Invasive Neurosurg 53:147-152, 2010

3. Kim JS, Choi G, Lee SH: Percutaneous endoscopic lumbar discectomy via contralateral approach: a technical case report. Spine 36:1173-1178, 2011

4. Kim SS, Michelsen CB: Revision Surgery for failed back surgery syndrome. Spine 17:957-960, 1992

5. Lee S, Kim SK, Lee SH, Kim WJ, Choi WC, Choi G, et al: Percutaneous endoscopic lumbar discectomy for migrated disc herniation: classification of disc migration and surgical approaches. Eur Spine J 16:431-437, 2007

6. Rasouli MR, Rahimi-Movaghar V, Shokraneh F, Moradi-Lakeh M, Chou R: Minimally invasive discectomy versus microdiscectomy/open discectomy for symptomatic lumbar disc herniation. Cochrane Database of Systematic Reviews Issue 9, 2014

7. Du J, Tang X, Jing X, Li N, Wang Y, Zhang X: Outcomes of percutaneous endoscopic lumbar discectomy via a translaminar approach, especially for soft, highly down-migrated lumbar disc herniation. Int Orthop 11, 2016 